\title{
High occurrence of zoonotic subtypes of Cryptosporidium parvum in Cypriot dairy
} farms

Sumaiya Hoque ${ }^{1}$, Daphne E. Mavrides ${ }^{2}$, Pedro Pinto ${ }^{1}$, Silvia Costas ${ }^{1, \#}$, Nisa Begum ${ }^{1, \#,}$ Claudia Azevedo-Ribeiro ${ }^{1}$, Maria Liapi ${ }^{3}$ Martin Kváč $^{4,5}$, Stavros Malas ${ }^{2}$, Eleni Gentekaki ${ }^{6,7}$ and Anastasios D. Tsaousis ${ }^{1,2, *}$

${ }^{1}$ Laboratory of Molecular and Evolutionary Parasitology, RAPID group, School of Biosciences, University of Kent, Canterbury, UK

${ }^{2}$ University of Nicosia Medical School, Department of Basic Sciences, Nicosia, Cyprus

${ }^{3}$ Veterinary Services of Cyprus, Nicosia, Cyprus

${ }^{4}$ Institute of Parasitology, Biology Centre CAS, České Budějovice, Czech Republic

${ }^{5}$ Faculty of Agriculture, University of South Bohemia in České Budějovice, Czech Republic

${ }^{6}$ School of Science, Mae Fah Luang University, Chiang Rai, Thailand, 57100

${ }^{7}$ Gut Microbiome Research Group, Mae Fah Luang University, Chiang Rai, Thailand, 57100

\# equal contribution

*Corresponding author: Dr. Anastasios D. Tsaousis ( $\underline{\text { A.Tsaousis@kent.ac.uk } /}$

tsaousis.anastasios@gmail.com) School of Biosciences, University of Kent, Canterbury, CT2 7NJ, UK 


\begin{abstract}
Cryptosporidium parvum is one of the major causes of neonatal calf diarrhoea resulting in reduced farm productivity and compromised animal welfare worldwide. Livestock act as a major reservoir of this parasite, which can be transmitted to humans directly and/or indirectly, posing a public health risk. Research reports on Cryptosporidium prevalence from the east Mediterranean region are scarce with even less originating from Cyprus. This study is the first to explore occurrence of Cryptosporidium spp. in young dairy calves on the island. A total of 242 faecal samples were collected from 10 dairy cattle farms in Cyprus, all of which were screened for Cryptosporidium spp. using nested-PCR amplification targeting the small subunit of the ribosomal RNA (18S rRNA) gene. The $60 \mathrm{kDa}$ glycoprotein (gp60) gene was also sequenced for the samples identified as C. parvum positive to determine the subtypes present. Occurrence of Cryptosporidium was 43.8\% (106/242) with at least one positive isolate in each farm sampled. Prevalence per farm ranged from 20-64\%, while C. bovis, C. ryanae and C. parvum were the only species identified. Amongst those, the latter was the predominant species, representing $51.8 \%$ of all positive samples. Four zoonotic subtypes were identified IIaA14G1R1, IIaA15G1R1, IIaA15G2R1 and IIaA18G2R1. IIaA14G1R1 was the most abundant; representing $48.2 \%$ of all $C$. parvum positive samples and was also the most widespread. This is the first report of zoonotic subtypes of $C$. parvum circulating in Cyprus. These results highlight the need for further research into the parasite focusing on its diversity, prevalence, host-range and transmission dynamics on the island.
\end{abstract}




\section{Introduction}

Cryptosporidium is an apicomplexan parasite and the causative agent of cryptosporidiosis [1]. Clinical signs of this disease include watery diarrhoea and dehydration, which can prove fatal, particularly in immunocompromised individuals and infants [2,3]. The transmission form of the parasite is the oocyst, which can be transmitted directly via the faecal-oral route or indirectly, through contaminated food and water [1]. Oocysts are very robust, highly resistant to environmental changes and can remain dormant for up to six months [1,4]. Millions of oocysts can be shed through bowel movements of infected hosts, both humans and other animals. Coupled with the lack of effective therapeutic agents and vaccines [5,6], it has proven difficult to manage outbreaks and the spread of Cryptosporidium. The outbreaks are commonly of zoonotic nature with farms constituting a major reservoir of the parasite [7].

Of the 49 described Cryptosporidium species, around 20 of them are zoonotic [8,9]. Molecular surveillance of Cryptosporidium outbreaks indicates that C. parvum is responsible for the majority of human cryptosporidiosis cases [10,11]. Amongst farm animals, goats and cattle are the main hosts of the organism. In cattle farms, C. andersoni, C. bovis, C. ryanae and C. parvum are the infectious species. Age-related variance of infecting Cryptosporidium species has been shown, with $C$. parvum typically infecting neonatal calves, while the others are typically found in cows, heifers and post-weaned calves [12]. Cryptosporidium parvum is the most clinically significant as the most widespread species in cattle [13-15], a major cause of enteritis, causing neonatal diarrhoea and subsequent long-term adverse effects on weight gain $[6,13,16]$. The disease leads to significant economic losses for cattle farmers due to reduced production efficiency of meat and milk [17-19]. Aside from the financial impact of Cryptosporidium infection, cattle have been well established as a key source of zoonotic cryptosporidiosis giving an epidemiological dimension to the issue [5,20,21].

Prevalence investigations have frequently been carried out in almost all continents [22,23]. Studies of Cryptosporidium occurrence in Europe point towards a high prevalence [24-26]. These investigations have primarily focused on mainland Europe, while island nations have been overlooked with the exception of the UK [27]. Island settings are ideal for studying epidemiological and ecological aspects of parasitic organisms due to restricted boundaries and subsequent limited movement of hosts. Regrettably, there is lack of information on the prevalence and subtypes of Cryptosporidium spp. circulating in small European island nations.

This study fills the gap of scant molecular epidemiological data on Cryptosporidium spp. in dairy cattle in Cyprus. The island is the third largest in the Mediterranean region and is in the cross paths of three continents. Using molecular techniques and analyses, we were able to 
identify Cryptosporidium species and subtypes circulating within the examined cattle farms. This work will spearhead further studies on investigating the role and effect of the parasite in this unique region of the world.

\section{Methods}

\section{Study area}

Samples were collected from ten randomly selected farms located in two districts of Cyprus, namely Larnaca and Nicosia (Figure 1). These two districts were chosen due to the high density of cattle farms. Eight farms were located in Nicosia and two in Larnaca. The Nicosia district lies in the centre of the island and samples were taken from the Dali, Tseri, Ayia Varvara, Akaki and Arediou regions. Most of the selected farms in Nicosia are at a relatively low altitude (200-400 m) experiencing hot, dry and humid summers and cold winters with minimal precipitation. The two farms in the Larnaca district were located in the Aradippou region, which has a great confluence of farms. The area experiences a similar climate to that of Nicosia with slightly elevated humidity due to a closer proximity to the sea and a lower altitude $(80 \mathrm{~m})$. Farmers were invited to participate to the study by the employed veterinarian, who also explained the research project and its overall aims and objectives. The study was under the umbrella of the national Veterinary Services. Cows from all selected farms were of the dairy producing Holstein Friesian breed. All participating farms raised their cows semi-intensively.

\section{Sample collection and DNA extraction}

242 faecal samples were collected in November 2019. Samples ranged from preweaned calves up to three months of age and animals were randomly selected. Faeces were collected immediately after defecation, placed in sterile tubes and stored on ice. Tubes were stored at $-20{ }^{\circ} \mathrm{C}$ upon arrival to the laboratory. DNA extraction was carried out using $200 \mathrm{mg}$ of faeces per sample and the PureLink ${ }^{\mathrm{TM}}$ Microbiome DNA Purification Kit (Thermo Fisher Scientific, California, USA) according to manufacturer's instructions, with slight modifications. Specifically, $650 \mu \mathrm{l}$ of S1 Lysis Buffer was used for each sample. After addition of S2 Lysis enhancer, samples were incubated for $13 \mathrm{~min}$ at $65^{\circ} \mathrm{C}$, and homogenised for a further $13 \mathrm{~min}$. Following addition of S3 Clean-up Buffer, samples were incubated at $4{ }^{\circ} \mathrm{C}$ to optimise removal of proteins. After addition of $100 \mu \mathrm{l}$ S6 Elution Buffer, samples were incubated at room temperature for 3 min before centrifugation to improve DNA yield. Genomic 
DNA was stored at $-20{ }^{\circ} \mathrm{C}$ until amplification reactions of the small subunit ribosomal RNA (18S rRNA) and $60 \mathrm{kDa}$ glycoprotein (gp60) genes were carried out.

\section{Cryptosporidium spp. screening and molecular genotyping}

Samples were screened for Cryptosporidium spp. using nested-PCR amplification of a $631 \mathrm{bp}$ region of the $18 S$ rRNA gene [28]. The external primers used were 5'GATTAAGCCATGCATGTCTAA-3' (forward) and 5'-TTCCATGCTGGAGTATTCAAG3' (reverse). The internal primers were 5'-CAGTTATAGTTTACTTGATAATC-3' (forward) and 5'-CCTGCTTTAAGCACTCTAATTTTC-3' (reverse). Each PCR mixture contained $1 \mu 1$ of DNA, $0.4 \mu \mathrm{M}$ of each forward and reverse primers, $12.5 \mu 1$ of $2 \times$ PCRBIO Taq Mix Red (PCR Biosystems, London, UK) and $9.5 \mu$ nuclease-free water. Cycling conditions for the external PCR were as follows: a denaturation step for 2 min at $94{ }^{\circ} \mathrm{C}$, followed by 24 cycles at $94{ }^{\circ} \mathrm{C}$ for $50 \mathrm{~s}$, annealing at $53^{\circ} \mathrm{C}$ for $50 \mathrm{~s}$ and extension at $72{ }^{\circ} \mathrm{C}$ for $1 \mathrm{~min}$, and a final extension step at $72{ }^{\circ} \mathrm{C}$ for $10 \mathrm{~min}$.

Cycling conditions for the internal PCR were a denaturation step for $2 \mathrm{~min}$ at $94{ }^{\circ} \mathrm{C}$, followed by 30 cycles at $94{ }^{\circ} \mathrm{C}$ for $50 \mathrm{~s}$, annealing at $56^{\circ} \mathrm{C}$ for $30 \mathrm{~s}$ and extension at $72{ }^{\circ} \mathrm{C}$ for $1 \mathrm{~min}$, and a final extension step at $72{ }^{\circ} \mathrm{C}$ for $10 \mathrm{~min}$. Positive (genomic DNA from a pure culture of C. parvum) and negative (water was used as template instead of DNA) controls were included in both reactions. PCR products were separated on a $2 \%$ gel and extracted using GeneJET Gel Extraction Kit (Thermo Fisher Scientific, California, USA). Samples were bidirectionally sequenced (Eurofins Genomics) using the internal PCR primers.

Chromatograms were manually assessed for quality and ambiguous bases were trimmed on both ends of the reads. For species level identification, sequences were used as queries to perform BLAST searches against the nucleotide database in GenBank followed by alignment with reference sequences.

\section{Cryptosporidium screening and gp60 subtyping}

To determine the subtype of Cryptosporidium $18 S$ rRNA PCR-positive samples, nested PCR of the gp60 gene was carried out [29]. The external primers used were 5'ATAGTCTCCGCTGTATTC- 3' (forward) and 5'-GGAAGGAACGATGTATCT-3' (reverse). The internal primers were 5'-TCCGCTGTATTCTCAGCC- 3' (forward) and 5'GCAGAGGAACCAGCATC-3' (reverse). Each PCR mixture contained $2 \mu$ of DNA, $0.2 \mu \mathrm{M}$ each of forward and reverse primers, $15 \mu \mathrm{l}$ of $2 \times$ PCRBIO Taq Mix Red (PCR Biosystems) and $11.8 \mu \mathrm{l}$ nuclease-free water. Cycling conditions for both internal and external PCR 
reactions were: a denaturation step for $3 \mathrm{~min}$ at $94{ }^{\circ} \mathrm{C}$, followed by 35 cycles at $94{ }^{\circ} \mathrm{C}$ for $45 \mathrm{~s}$, annealing at $50{ }^{\circ} \mathrm{C}$ for $45 \mathrm{~s}$ and extension at $72{ }^{\circ} \mathrm{C}$ for $1 \mathrm{~min}$, and a final extension step at 72 ${ }^{\circ} \mathrm{C}$ for $7 \mathrm{~min}$. Positive and negative controls were as described above and included in both reactions. PCR products were separated on a $2 \%$ gel and extracted using GeneJET Gel Extraction Kit (Thermo Fisher Scientific, California, USA). Samples were bidirectionally sequenced (Eurofins Genomics) using the internal PCR primers. Chromatograms were manually assessed for quality and ambiguous bases were trimmed on both ends of the reads. Subtypes were determined using established standard nomenclature [30]. Newly-generated sequences were used as queries to perform BLAST searches against the nucleotide database in GenBank followed by alignment with reference sequences. Polymorphisms were identified using these alignments.

\section{Results}

\section{Cryptosporidium spp. occurrence across Cypriot farms}

Amplification of the $18 S$ rRNA gene showed an occurrence of $43.8 \%$ with 106/242 specimens positive for Cryptosporidium spp. (Table 1). Occurrence varied across farms from $20 \%(3 / 15)$ to $64 \%(16 / 25)$.

The majority of the positive samples were identified as C. parvum $(47.2 \%, 50 / 106)$ with 41 of them showing $100 \%$ nucleotide identity to the reference sequence AH006572.2, and one sample showing $99 \%$ nucleotide identity to the same sequence. We were unable to obtain good quality sequences for eight $18 S$ rRNA PCR-positive samples. Nonetheless, C. parvum identity was confirmed through positive gp60 PCR and subsequent sequencing. At the farm level, $C$. parvum was present in $9 / 10$ farms, with occurrence ranging from $9.1 \%$ to $34.8 \%$.

The next most common species present was C. ryanae $(25.5 \%, 27 / 106)$. Additionally, six samples from three farms had co-infections of C. ryanae and C. parvum, with their presence determined through $18 S$ rRNA and gp 60 amplification, respectively. Twenty-nine samples had $100 \%$ nucleotide identity to the reference sequence KF128756.1, while one was $99 \%$ identical to the same sequence. Another variant of $C$. ryanae was identified with three samples having 100\% nucleotide identity to the reference sequence KT922233.1. Cryptosporidium bovis was the least prevalent species present $(21.7 \%, 23 / 106)$ with all 23 samples showing $100 \%$ nucleotide identity to the reference sequence EU827363.2. Representative nucleotide sequences of $18 S$ rRNA have been deposited in GenBank under accession numbers OL348064OL348160. 


\section{Cryptosporidium parvum subtyping through gp60 analysis}

All 50 of $18 S$ rRNA PCR-positive samples were screened using nested-PCR of the gp60 gene. Of these, the gp60 gene was successfully amplified and sequenced in 42 samples and then subtyped for C. parvum. A further five gp60 positive samples were identified as $C$. ryanae. Sequence analysis revealed the presence of five subtypes, all belonging to the IIa $C$. parvum family (Table 2). Nine of the farms sampled contained at least one C. parvum subtype.

The IIaA14G1R1 subtype was the most numerically prevalent occurring in $60 \%$ of the farms, making it also the most widely distributed. It was the sole subtype present on three farms and represented $57.4 \%(27 / 47)$ of all C. parvum positive samples with successful gp60 sequencing. All 27 showed 100\% nucleotide identity to the reference sequence MN815774.1. The IIaA12G1R1 subtype was the next most prevalent and was only found in one farm, accounting for $29.7 \%$ (14/47) of all C. parvum infections. All 14 samples were identical and showed 99\% nucleotide identity to the reference sequence MW411017.1. Four samples were identified as IIaA15G2R1, with two of them showing 100\% nucleotide identity to the reference sequence DQ630518.1, while the other two were 99\% identical with the same sequence. One sample was identified as IIaA15G1R1, with 99\% nucleotide identity to the reference sequence AB777872.1 and another was identified as IIaA18G2R1, with 99\% nucleotide identity to the reference sequence DQ630515.1 (Table 3). Representative nucleotide sequences of gp60 have been deposited in GenBank under accession numbers OL462897- OL462943.

\section{Geographical distribution of subtypes}

For easy visualization, subtype names are also indicated by their colour as depicted in Figure 2. The most broadly distributed subtype is IIaA14G1R1 (red), present in 6/9 (67\%) of C. parvum positive farms, followed by IIaA15G2R1 (green), present in 3/9 (33\%) farms. In all cases, the IIaA15G2R1 (green) subtype co-occurred with another and was the least dominant of the two. In two cases, co-occurrence was with IIaA14G1R1 (red) and in one with IIaA12G1R1 (orange). The latter subtype, along with IIaA18G2R1 (yellow) and IIaA15G1R1 (blue) occurred only in one farm each. In four farms only a single subtype was detected, IIaA14G1R1 (red) in three and IIaA15G1R1 (blue) in one. Notably, in Larnaca, the two sampled farms were in very close proximity, but the subtypes present did not overlap. One farm had only IIaA14G1R1 (red) subtype, while the other had IIaA12G1R1 (orange) and IIaA15G2R1 (green). 


\section{Discussion}

This is the first study investigating Cryptosporidium spp. occurrence on dairy farms of Cyprus. The study focused exclusively on young calves up to three months of age. The overall occurrence of the parasite was $43.8 \%$. Previous molecular studies in the surrounding Mediterranean region have generally reported lower incidences of Cryptosporidium infection amongst cattle. Specifically, studies using PCR followed by $18 S$ rRNA sequencing in Turkey found prevalence ranging from 3.9-53.6\% [31-35]. In Egypt, subtype based prevalence was between 7-30.2\% [36-40]. A small-scale PCR-based study in Jordan found $18.7 \%$ of asymptomatic cattle carried the organism [41]. The discrepancy in prevalence observed among these studies may be due to various factors, including age of cows, farm/herd location, seasonality, farm management, and method of detection. Due to time and financial constraints, microscopic analysis of faeces is a popular screening method, where only microscopically positive samples undergo molecular genotyping. While these studies do provide information on Cryptosporidium species and C. parvum subtypes present, they likely underestimate prevalence due to the reduced sensitivity of microscopy. Additionally, some studies only targeted diarrheic animals [33, 35], possibly inflating incidence of Cryptosporidium reported. Nonetheless, this is not an accurate representation of occurrence of the parasite in the overall cattle population, as it does not include healthy animals. Herein, we used a nested PCR approach to identify and subtype (see below) Cryptosporidium, which is a more sensitive and specific method. At the farm level, Cryptosporidium was broadly distributed across all. This finding matches previous flock-level studies in goats and sheep in Cyprus [42]. Even though this is a preliminary finding, it shows that the parasite is widespread in this region hinting at its potential of zoonotic transmission. To that end, follow up studies should expand to include farms across the whole island. The variation in Cryptosporidium occurrence per farm could indicate differences in farm management practices. Climate variables, such as temperature and precipitation, may also play a part in Cryptosporidium spread [43,44], with some studies showing seasonal variation in Cryptosporidium prevalence in cattle farms [45]. Nonetheless, in this study, there was no precipitation and minimal variation in temperature in the region during the sampling period (see Supplementary Material, S1). As such, future investigations should report these along with potential risk factors - e.g., calf husbandry practices, box 
dynamics, bedding, colostrum feeding schedule, climate and geographical variables - to understand their impact in parasite spreading.

Cryptosporidium parvum was the most numerically predominant species present, representing $51.8 \%$ of total infections, followed by C. ryanae at $31.1 \%$ and C. bovis at $21.7 \%$. Our results on predominance of $C$. parvum are in agreement with those from surrounding regions in both healthy and diarrheic animals [31,35,36,46-48]. The predominance of $C$. parvum specifically in pre-weaned cattle has also been reported in the USA [12]. At the farm level, C. parvum and C. ryanae were found in $90 \%$ of the farms, while C. bovis was present in 60\%. Cryptosporidium ryanae and C. bovis infections are typically asymptomatic and occur in older animals. Since this study focused on pre-weaned and young calves, it is possible that these two species might be underrepresented. Hence, future studies should focus on a wider age range of cattle.

Amongst the 55 C. parvum positive samples identified with $18 S$ rRNA including coinfections, only 47 were subtyped. The rest of the samples could not be subtyped due to unclear sequence chromatograms. This could suggest that the calves from which the samples were obtained carried multiple subtypes of $C$. parvum. A combination of metagenomics and upcoming methodologies will assist in tackling this common issue in the future. The predominant $C$. parvum subtypes found in this study do not correspond to those of surrounding countries. For instance, in Turkey the endemic subtype is IIaA13G2R1. In Egypt, the IId family is the most commonly found in cows, with IIdA20G1 subtype being endemic [37-40,46,49]. Herein, the most numerically abundant C. parvum subtype was IIaA14G1R1 (red colour, Figure 2) and it was also the most widespread, having been found in 6/10 farms. This subtype has been reported previously in cows from Turkey [31], Austria [50,51], Estonia [52], Poland [53], Germany [54] and the Netherlands [24], though it was typically less abundant in all cases. Outbreaks of human cryptosporidiosis in Norway and New Zealand [55,56] have been attributed to IIaA14G1R1, and the subtype has also been found in human samples from the USA [57], Ethiopia [58], Slovenia [59] and Slovakia [60]. In the UK, IIaA14G1R1 was found in animal housing premises that had been identified as potential sources of transmission [61]. This is the first report of IIaA14G1R1 as the predominant subtype circulating in a region highlighting its zoonotic potential. However, as this study had a relatively small sample size, the subtypes identified here may not be indicative of the entire cattle population in this country.

The IIaA12G1R1 (orange, Figure 2) comprised 25.4\% of C. parvum positive samples and it was identified only in a single farm. Previously, IIaA12G1R1 was detected in cows in Israel, making this report the second one in the region [47]. Zoonotic potential of this subtype 
remains to be determined, having so far only been reported in animals. The IIaA15G2R1 (green, Figure 2) subtype is the most predominant worldwide [62], including the neighbouring countries Turkey [63] and Israel [47]. However, it occurred at relatively low levels in the Cypriot farms studied (8.5\%). IIaA15G2R1 is responsible for the majority of acute clinical disease in humans, hence, its zoonotic potential has been well established [14,62]. Nonetheless, our results indicate it may not play a key role in zoonotic transmission in Cyprus, though this needs further investigation with larger sample sizes.

A single isolate of each IIaA15G1R1 (blue, Figure 2) and IIaA18G2R1 (yellow, Figure 2) were also detected. In cattle, IIaA15G1R1 has been found in Egypt [36,39], Sweden [64] and Czech Republic [65]. Its zoonotic potential appears to be high, having been linked to numerous instances of human cryptosporidiosis globally. For instance, in Scotland, IIaA15G1R1 was responsible for 47\% of human cryptosporidiosis cases [66]. The subtype has also been identified in humans with diarrhoea from England [67], Australia [68], Egypt [46], Slovenia [59] and Lebanon [69]. IIaA18G2R1 has been previously identified in cattle in the USA [70], Northern Ireland [71], Germany [72], Italy [73] and France [24], though typically was one of the less common subtypes found. This is a potentially zoonotic subtype having been identified sporadically in humans from England [67], USA [57,74] and Australia [75].

\section{Conclusions}

To date, there have been no studies on human cryptosporidiosis in Cyprus [76]. Despite this, our study revealed a high occurrence of C. parvum (90\%) in dairy calves and presence of four zoonotic subtypes in cattle farms. This brings into question the circulation of the various subtypes not only in calves but also in human and other animal hosts as well as the environment. It's worth noting that Cyprus imports cattle from Austria, Czech Republic, Denmark, Germany, Italy and the Netherlands for both breeding and production purposes. Hence, screening these animals for Cryptosporidium spp. would help track circulation and introduction of various subtypes across the different countries. While this report represents a first step in determining Cryptosporidium burden in cattle in Cyprus, significant gaps on prevalence, transmission dynamics, sources of infection and effective interventions remain, calling into attention the need for a One Health approach in the immediate future. 
Author Contributions: Conceptualization, A.D.T.; methodology, S.H., D.E.M., P.P, C.A.R., N.B., and S.C.; software, M.K.; validation, S.H. P.P., M.K. E.G. and A.D.T.; formal analysis, S.H. and D.E.M.; investigation, S.H., M.L., and D.E.M.; resources, A.D.T. and S.M.; data curation, M.K.; writing — original draft preparation, S.H.; writing — review and editing, D.E.M., E.G. and A.D.T.; supervision, A.D.T. and S.M.; project administration, S.M. and A.D.T.; funding acquisition, A.D.T. . All authors have read and agreed to the published version of the manuscript.

Funding: This project has received funding from the Interreg 2 Seas programme 2014-2020 co-funded by the European Regional Development Fund under subsidy contract No 2S05043.

Institutional Review Board Statement: This study was only focusing on the collection of the faecal samples from selected dairy cows under the supervision of expert veterinarians and thus there were no ethical implications. Consequently, there was no need for perusal of any further ethical approvals.

Informed Consent Statement: Not applicable.

Data Availability Statement: All data have been submitted to GenBank as shown in the methods section.

Acknowledgments: We'd like to thank University of Nicosia for funding this work. S.H. studentship was funded by the Health-4-Dairy cows (H4DC) Interreg-2-seas programme. We are grateful to farmers and veterinarians in Cyprus who participated in this study.

Conflicts of Interest: The authors declare no conflict of interest.

\section{References}

1. Shirley, D.-A. T.; Moonah, S. N.; Kotloff, K. L. Burden of Disease from Cryptosporidiosis. Curr. Opin. Infect. Dis. 2012, 25 (5), 555. https://doi.org/10.1097/QCO.0B013E328357E569.

2. Carter, B. L.; Chalmers, R. M.; Davies, A. P. Health Sequelae of Human Cryptosporidiosis in Industrialised Countries: A Systematic Review. Parasit. Vectors 
2020, 13 (1), 1-14. https://doi.org/10.1186/S13071-020-04308-7.

3. Vanathy, K.; Parija, C.; Mandal, J.; Hamide, A.; Krishnamurthy, S. Cryptosporidiosis: A Mini Review. Trop. Parasitol. 2017, 7 (2), 72. https://doi.org/10.4103/tp.TP_25_17.

4. King, B. J.; Monis, P. T. Critical Processes Affecting Cryptosporidium Oocyst Survival in the Environment. Parasitology 2007, 134 (3), 309-323. https://doi.org/10.1017/S0031182006001491.

5. Mosier, D. A.; Oberst, R. D. Cryptosporidiosis: A Global Challenge. Ann. N. Y. Acad. Sci. 2000, 916 (1), 102-111. https://doi.org/10.1111/J.1749-6632.2000.TB05279.X.

6. Thomson, S.; Hamilton, C. A.; Hope, J. C.; Katzer, F.; Mabbott, N. A.; Morrison, L. J.; Innes, E. A. Bovine Cryptosporidiosis: Impact, Host-Parasite Interaction and Control Strategies. Vet. Res. 2017, 48 (1). https://doi.org/10.1186/S13567-017-0447-0.

7. Hatam-Nahavandi, K.; Ahmadpour, E.; Carmena, D.; Spotin, A.; Bangoura, B.; Xiao, L. Cryptosporidium Infections in Terrestrial Ungulates with Focus on Livestock: A Systematic Review and Meta-Analysis. Parasit. Vectors 2019, 12 (1), 1-23. https://doi.org/10.1186/S13071-019-3704-4.

8. Ježková, J.; Limpouchová, Z.; Prediger, J.; Holubová, N.; Sak, B.; Konečný, R.; Květoňová, D.; Hlásková, L.; Rost, M.; McEvoy, J.; Rajský, D.; Feng, Y.; Kváč, M. Cryptosporidium Myocastoris n. Sp. (Apicomplexa: Cryptosporidiidae), the Species Adapted to the Nutria (Myocastor Coypus). Microorganisms 2021, 9 (4), 813. https://doi.org/10.3390/MICROORGANISMS9040813.

9. Prediger, J.; Ježková, J.; Holubová, N.; Sak, B.; Konečný, R.; Rost, M.; McEvoy, J.; Rajský, D.; Kváč, M. Cryptosporidium sciurinum n. Sp. (Apicomplexa: Cryptosporidiidae) in Eurasian Red Squirrels (Sciurus vulgaris). Microorganisms 2021, 9 (10), 2050. https://doi.org/10.3390/MICROORGANISMS9102050.

10. Leitch, G. J.; He, Q. Cryptosporidiosis-an Overview. J. Biomed. Res. 2011, 25 (1), 1. https://doi.org/10.1016/S1674-8301(11)60001-8.

11. Xiao, L.; Feng, Y. Zoonotic Cryptosporidiosis. FEMS Immunol. Med. Microbiol. 2008, 52 (3), 309-323. https://doi.org/10.1111/J.1574-695X.2008.00377.X.

12. Santín, M.; Trout, J. M.; Xiao, L.; Zhou, L.; Greiner, E.; Fayer, R. Prevalence and Age-Related Variation of Cryptosporidium Species and Genotypes in Dairy Calves. Vet. Parasitol. 2004, 122 (2), 103-117. https://doi.org/10.1016/J.VETPAR.2004.03.020.

13. Cho, Y.-I.; Yoon, K.-J. An Overview of Calf Diarrhea - Infectious Etiology, Diagnosis, and Intervention. J. Vet. Sci. 2014, 15 (1), 1-17.

https://doi.org/10.4142/JVS.2014.15.1.1.

14. Feng, Y.; Ryan, U. M.; Xiao, L. Genetic Diversity and Population Structure of Cryptosporidium. Trends Parasitol. 2018, 34 (11), 997-1011.

https://doi.org/10.1016/J.PT.2018.07.009.

15. De Graaf, D. C.; Vanopdenbosch, E.; Ortega-Mora, L. M.; Abbassi, H.; Peeters, J. E. A Review of the Importance of Cryptosporidiosis in Farm Animals. Int. J. Parasitol. 1999, 29 (8), 1269-1287. https://doi.org/10.1016/S0020-7519(99)00076-4.

16. Shaw, H. J.; Innes, E. A.; Morrison, L. J.; Katzer, F.; Wells, B. Long-Term Production Effects of Clinical Cryptosporidiosis in Neonatal Calves. Int. J. Parasitol. 2020, 50 (5), 371-376. https://doi.org/10.1016/J.IJPARA.2020.03.002.

17. Stott, A.; Gunn, G. A Comparison of Economic Losses Due to Calf Enteritis and Calf Pneumonia in Northern Scotland. Epidémiologie santé Anim. 1997.

18. Hawkins, A.; Burdine, K.; Amaral-Phillips, D.; Costa, J. H. C. An Economic Analysis of the Costs Associated with Pre-Weaning Management Strategies for Dairy Heifers. Anim. 2019, 9 (7), 471. https://doi.org/10.3390/ANI9070471.

19. Bennett, R. The "direct Costs" of Livestock Disease: The Development of a System of 
Models for the Analysis of 30 Endemic Livestock Diseases in Great Britain. J. Agric. Econ. 2003, 54 (1), 55-71. https://doi.org/10.1111/J.1477-9552.2003.TB00048.X.

20. Widmer, G.; Carmena, D.; Kváč, M.; Chalmers, R. M.; Kissinger, J. C.; Xiao, L.; Sateriale, A.; Striepen, B.; Laurent, F.; Lacroix-Lamandé, S.; Gargala, G.; Favennec, L. Update on Cryptosporidium Spp.: Highlights from the Seventh International Giardia and Cryptosporidium Conference. In Parasite; EDP Sciences, 2020; Vol. 27, p 14. https://doi.org/10.1051/PARASITE/2020011.

21. Chalmers, R. M.; Giles, M. Zoonotic Cryptosporidiosis in the UK - Challenges for Control. J. Appl. Microbiol. 2010, 109 (5), 1487-1497. https://doi.org/10.1111/J.13652672.2010.04764.X.

22. Dong, S.; Yang, Y.; Wang, Y.; Yang, D.; Yang, Y.; Shi, Y.; Li, C.; Li, L.; Chen, Y.; Jiang, ' Qingwu; Zhou, Y. Prevalence of Cryptosporidium Infection in the Global Population: A Systematic Review and Meta-Analysis. Acta Parasitol. 1234, 65. https://doi.org/10.2478/s11686-020-00230-1.

23. Abeywardena, H.; Jex, A. R.; Gasser, R. B. A Perspective on Cryptosporidium and Giardia, with an Emphasis on Bovines and Recent Epidemiological Findings. Adv. Parasitol. 2015, 88, 243-301. https://doi.org/10.1016/BS.APAR.2015.02.001.

24. Pinto, P.; Ribeiro, C. A.; Hoque, S.; Hammouma, O.; Leruste, H.; Détriché, S.; Canniere, E.; Daandels, Y.; Dellevoet, M.; Roemen, J.; Bourgeois, A. B.; Kváč, M.; Follet, J.; Tsaousis, A. D. Cross-Border Investigations on the Prevalence and Transmission Dynamics of Cryptosporidium Species in Dairy Cattle Farms in Western Mainland Europe. Microorganisms 2021, 9 (11), 2394. https://doi.org/10.3390/microorganisms9112394.

25. Plutzer, J.; Lassen, B.; Jokelainen, P.; Djurković-Djaković, O.; Kucsera, I.; DorbekKolin, E.; Šoba, B.; Sréter, T.; Imre, K.; Omeragić, J.; Nikolić, A.; Bobić, B.; Živičnjak, T.; Lučinger, S.; Stefanović, L. L.; Kučinar, J.; Sroka, J.; Deksne, G.; Keidāne, D.; Kváč, M.; Hůzová, Z.; Karanis, P. Review of Cryptosporidium and Giardia in the Eastern Part of Europe, 2016. Eurosurveillance 2018, 23 (4), 16-00825. https://doi.org/10.2807/1560-7917.ES.2018.23.4.16-00825.

26. Cacciò, S. M.; Chalmers, R. M. Human Cryptosporidiosis in Europe. Clin. Microbiol. Infect. 2016, 22 (6), 471-480. https://doi.org/10.1016/J.CMI.2016.04.021.

27. Smith, R. P.; Clifton-Hadley, F. A.; Cheney, T.; Giles, M. Prevalence and Molecular Typing of Cryptosporidium in Dairy Cattle in England and Wales and Examination of Potential On-Farm Transmission Routes. Vet. Parasitol. 2014, 204 (3-4), 111-119. https://doi.org/10.1016/J.VETPAR.2014.05.022.

28. Ziegler, P. E.; Santucci, F.; Lindergard, G.; Nydam, D. V; Wade, S. E.; Schaaf, S. L.; Chang, Y.-F.; Mohammed, H. O. Evaluation of Polymerase Chain Reaction Diagnosis of Cryptosporidium Spp in Dairy Cattle and Wildlife. Vet. Ther. 2007, 8 (2), 148-159.

29. Alves, M.; Xiao, L.; Sulaiman, I.; Lal, A. A.; Matos, O.; Antunes, F. Subgenotype Analysis of Cryptosporidium Isolates from Humans, Cattle, and Zoo Ruminants in Portugal. J. Clin. Microbiol. 2003, 41 (6), 2744-2747.

https://doi.org/10.1128/JCM.41.6.2744-2747.2003/ASSET/37EE65F9-CC0B-4896A1B1-D229E6BCF55D/ASSETS/GRAPHIC/JM0631607002.JPEG.

30. Sulaiman, I. M.; Hira, P. R.; Zhou, L.; Al-Ali, F. M.; Al-Shelahi, F. A.; Shweiki, H. M.; Iqbal, J.; Khalid, N.; Xiao, L. Unique Endemicity of Cryptosporidiosis in Children in Kuwait. J. Clin. Microbiol. 2005, 43 (6), 2805. https://doi.org/10.1128/JCM.43.6.2805-2809.2005.

31. Yildirim, A.; Adanir, R.; Inci, A.; Yukari, B. A.; Duzlu, O.; Onder, Z.; Ciloglu, A.; Simsek, E. Prevalence and Genotyping of Bovine Cryptosporidium Species in the Mediterranean and Central Anatolia Region of Turkey. Comp. Immunol. Microbiol. 
Infect. Dis. 2020, 69, 101425. https://doi.org/10.1016/J.CIMID.2020.101425.

32. Guven, E.; Avcioglu, H.; Balkaya, I.; Hayirli, A.; Kar, S.; Karaer, Z. Prevalence of Cryptosporidiosis and Molecular Characterization of Cryptosporidium Spp. in Calves in Erzurum. Kafkas Üniversitesi Vet. Fakültesi Derg. 2013, 19 (6), 969-974.

33. Yildirim, A.; Sevinc, F.; Onder, Z.; Duzlu, O.; Ekici, O. D.; Isik, N.; Ciloglu, A.; Simsek, E.; Yetismis, G.; Inci, A. Comparison of Three Diagnostic Methods in the Diagnosis of Cryptosporidiosis and Gp60 Subtyping of Cryptosporidium parvum in Diarrheic Calves in Central Anatolia Region of Turkey. Eurobiotech J. 2021, 5 (2), 63-69. https://doi.org/10.2478/EBTJ-2021-0010.

34. Ayan, A.; Orunc Kilinc, O.; Yuksek, N.; Basbugan, Y. Detection of Cryptosporidium Spp. in Calves through Nested PCR and Kinyoun's Acid-Fast Methods in Van, Turkey. Int. J. Ecosyst. Ecol. Sci. 2020, 10 (2), 271-276. https://doi.org/10.31407/ijees.

35. Kabir, M. H. Bin; Ceylan, O.; Ceylan, C.; Shehata, A. A.; Bando, H.; Essa, M. I.; Xuan, X.; Sevinc, F.; Kato, K. Molecular Detection of Genotypes and Subtypes of Cryptosporidium Infection in Diarrheic Calves, Lambs, and Goat Kids from Turkey. Parasitol. Int. 2020, 79, 102163. https://doi.org/10.1016/J.PARINT.2020.102163.

36. Naguib, D.; El-Gohary, A. H.; Mohamed, A. A.; Roellig, D. M.; Arafat, N.; Xiao, L. Age Patterns of Cryptosporidium Species and Giardia Duodenalis in Dairy Calves in Egypt. Parasitol. Int. 2018, 67 (6), 736-741.

https://doi.org/10.1016/J.PARINT.2018.07.012.

37. Amer, S.; Honma, H.; Ikarashi, M.; Tada, C.; Fukuda, Y.; Suyama, Y.; Nakai, Y. Cryptosporidium Genotypes and Subtypes in Dairy Calves in Egypt. Vet. Parasitol. 2010, 169 (3-4), 382-386. https://doi.org/10.1016/J.VETPAR.2010.01.017.

38. Ibrahim, M. A.; Abdel-Ghany, A. E.; Abdel-Latef, G. K.; Abdel-Aziz, S. A.; Aboelhadid, S. M. Epidemiology and Public Health Significance of Cryptosporidium Isolated from Cattle, Buffaloes, and Humans in Egypt. Parasitol. Res. 2016, 115 (6), 2439-2448. https://doi.org/10.1007/S00436-016-4996-3.

39. Amer, S.; Zidan, S.; Adamu, H.; Ye, J.; Roellig, D.; Xiao, L.; Feng, Y. Prevalence and Characterization of Cryptosporidium Spp. in Dairy Cattle in Nile River Delta Provinces, Egypt. Exp. Parasitol. 2013, 135 (3), 518-523. https://doi.org/10.1016/J.EXPPARA.2013.09.002.

40. Mahfouz, M. E.; Mira, N.; Amer, S. Prevalence and Genotyping of Cryptosporidium Spp. in Farm in Egypt. J. Vet. Med. Sci. 2014, 76 (12), 1569. https://doi.org/10.1292/JVMS.14-0272.

41. Hijjawi, N.; Mukbel, R.; Yang, R.; Ryan, U. Genetic Characterization of Cryptosporidium in Animal and Human Isolates from Jordan. Vet. Parasitol. 2016, 228, 116-120. https://doi.org/10.1016/J.VETPAR.2016.08.015.

42. Giadinis, N. D.; Symeoudakis, S.; Papadopoulos, E.; Lafi, S. Q.; Karatzias, H. Comparison of Two Techniques for Diagnosis of Cryptosporidiosis in Diarrhoeic Goat Kids and Lambs in Cyprus. Trop. Anim. Health Prod. 2012, 44 (7), 1561-1565. https://doi.org/10.1007/S11250-012-0106-4.

43. Jagai, J. S.; Castronovo, D. A.; Monchak, J.; Naumova, E. N. Seasonality of Cryptosporidiosis: A Meta-Analysis Approach. Environ. Res. 2009, 109 (4), 465. https://doi.org/10.1016/J.ENVRES.2009.02.008.

44. Lal, A.; Baker, M. G.; Hales, S.; French, N. P. Potential Effects of Global Environmental Changes on Cryptosporidiosis and Giardiasis Transmission. Trends Parasitol. 2013, 29 (2), 83-90. https://doi.org/10.1016/J.PT.2012.10.005.

45. Szonyi, B.; Bordonaro, R.; Wade, S. E.; Mohammed, H. O. Seasonal Variation in the Prevalence and Molecular Epidemiology of Cryptosporidium Infection in Dairy Cattle 
in the New York City Watershed. Parasitol. Res. 20101072 2010, 107 (2), 317-325. https://doi.org/10.1007/S00436-010-1864-4.

46. Helmy, Y. A.; Krücken, J.; Nöckler, K.; von Samson-Himmelstjerna, G.; Zessin, K. H. Molecular Epidemiology of Cryptosporidium in Livestock Animals and Humans in the Ismailia Province of Egypt. Vet. Parasitol. 2013, 193 (1-3), 15-24. https://doi.org/10.1016/J.VETPAR.2012.12.015.

47. Yasur-Landau, D.; Zilberberg, M.; Perry Markovich, M.; Behar, A.; Fleiderovitz, L.; Leszkowicz Mazuz, M. Cryptosporidium parvum Subtypes from Diarrheic Dairy Calves in Israel. Vet. Parasitol. Reg. Stud. Reports 2021, 25, 100608. https://doi.org/10.1016/J.VPRSR.2021.100608.

48. Kassouha, M.; Soukkarieh, C.; Alkhaled, A. First Genotyping of Cryptosporidium Spp. in Pre-Weaned Calves, Broiler Chickens and Children in Syria by PCR-RFLP Analysis. Vet. Parasitol. 2016, 225, 86-90. https://doi.org/10.1016/J.VETPAR.2016.06.009.

49. Amer, S.; Zidan, S.; Feng, Y.; Adamu, H.; Li, N.; Xiao, L. Identity and Public Health Potential of Cryptosporidium Spp. in Water Buffalo Calves in Egypt. Vet. Parasitol. 2013, 191 (1-2), 123-127. https://doi.org/10.1016/J.VETPAR.2012.08.015.

50. Lichtmannsperger, K.; Harl, J.; Freudenthaler, K.; Hinney, B.; Wittek, T.; Joachim, A. Cryptosporidium parvum, Cryptosporidium ryanae, and Cryptosporidium bovis in Samples from Calves in Austria. Parasitol. Res. 2020, 119 (12), 4291-4295. https://doi.org/10.1007/S00436-020-06928-5.

51. Lichtmannsperger, K.; Hinney, B.; Joachim, A.; Wittek, T. Molecular Characterization of Giardia intestinalis and Cryptosporidium parvum from Calves with Diarrhoea in Austria and Evaluation of Point-of-Care Tests. Comp. Immunol. Microbiol. Infect. Dis. 2019, 66, 101333. https://doi.org/10.1016/J.CIMID.2019.101333.

52. Santoro, A.; Dorbek-Kolin, E.; Jeremejeva, J.; Tummeleht, L.; Orro, T.; Jokelainen, P.; Lassen, B. Molecular Epidemiology of Cryptosporidium Spp. in Calves in Estonia: High Prevalence of Cryptosporidium parvum Shedding and 10 Subtypes Identified. Parasitology 2019, 146 (2), 261-267. https://doi.org/10.1017/S0031182018001348.

53. Kaupke, A.; Rzeżutka, A. Emergence of Novel Subtypes of Cryptosporidium parvum in Calves in Poland. Parasitol. Res. 2015, 114 (12), 4709-4716. https://doi.org/10.1007/S00436-015-4719-1.

54. Holzhausen, I.; Lendner, M.; Göhring, F.; Steinhöfel, I.; Daugschies, A. Distribution of Cryptosporidium parvum Gp60 Subtypes in Calf Herds of Saxony, Germany. Parasitol. Res. 2019, 118 (5), 1549-1558. https://doi.org/10.1007/S00436-019-062661.

55. Robertson, L. J.; Temesgen, T. T.; Tysnes, K. R.; Eikås, J. E. An Apple a Day: An Outbreak of Cryptosporidiosis in Norway Associated with Self-Pressed Apple Juice. Epidemiol. Infect. 2019, 147. https://doi.org/10.1017/S0950268819000232.

56. Garcia-R, J. C.; Pita, A. B.; Velathanthiri, N.; French, N. P.; Hayman, D. T. S. Species and Genotypes Causing Human Cryptosporidiosis in New Zealand. Parasitol. Res. 2020, 119 (7), 2317-2326. https://doi.org/10.1007/s00436-020-06729-w.

57. Herges, G. R.; Widmer, G.; Clark, M. E.; Khan, E.; Giddings, C. W.; Brewer, M.; McEvoy, J. M. Evidence That Cryptosporidium parvum Populations Are Panmictic and Unstructured in the Upper Midwest of the United States. Appl. Environ. Microbiol. 2012, 78 (22), 8096. https://doi.org/10.1128/AEM.02105-12.

58. Hailu, A. W.; Degarege, A.; Adamu, H.; Costa, D.; Villier, V.; Mouhajir, A.; Favennec, L.; Razakandrainibe, R.; Petros, B. Molecular Characterization of Cryptosporidium Spp. from Humans in Ethiopia. PLoS One 2021, 16 (6), e0253186. https://doi.org/10.1371/JOURNAL.PONE.0253186. 
59. SOBA, B.; LOGAR, J. Genetic Classification of Cryptosporidium Isolates from Humans and Calves in Slovenia. Parasitology 2008, 135 (11), 1263-1270. https://doi.org/10.1017/S0031182008004800.

60. Hatalová, E.; Valenčáková, A.; Luptáková, L.; Špalková, M.; Kalinová, J.; Halánová, M.; Bednárová, V.; Gabzdilová, J.; Dedinská, K.; Ondriska, F.; Boldiš, V. The First Report of Animal Genotypes of Cryptosporidium parvum in Immunosuppressed and Immunocompetent Humans in Slovakia. Transbound. Emerg. Dis. 2018, 66 (1), 243249.

61. Smith, R. P.; Newton, K.; Rimdap, E.; Wight, A.; Robinson, G.; Chalmers, R. M. Review of Investigations of Premises Housing Animals That Were Linked to Human Outbreaks of Cryptosporidiosis in England and Wales between 2009 and 2019. Vet. Rec. 2021, 189 (4). https://doi.org/10.1002/VETR.246.

62. Xiao, L. Molecular Epidemiology of Cryptosporidiosis: An Update. Exp. Parasitol. 2010, 124 (1), 80-89. https://doi.org/10.1016/J.EXPPARA.2009.03.018.

63. Arslan, M. O.; Itik Ekinci, A. Determination of Cryptosporidium parvum Subtypes in Cattle in Kars Province of Turkey. Kafkas Univ. Vet. Fak. Derg. 2014, 20 (2), 329. https://doi.org/10.9775/KVFD.2012.6565/ERR.

64. Silverlås, C.; Näslund, K.; Björkman, C.; Mattsson, J. G. Molecular Characterisation of Cryptosporidium Isolates from Swedish Dairy Cattle in Relation to Age, Diarrhoea and Region. Vet. Parasitol. 2010, 169 (3-4), 289-295.

https://doi.org/10.1016/J.VETPAR.2010.01.003.

65. Kváč, M.; Hromadová, N.; Květoňová, D.; Rost, M.; Sak, B. Molecular Characterization of Cryptosporidium Spp. in Pre-Weaned Dairy Calves in the Czech Republic: Absence of C. Ryanae and Management-Associated Distribution of $C$. andersoni, C. bovis and C. parvum Subtypes. Vet. Parasitol. 2011, 177 (3-4), 378382. https://doi.org/10.1016/J.VETPAR.2010.11.048.

66. Deshpande, A. P.; Jones, B. L.; Connelly, L.; Pollock, K. G.; Brownlie, S.; Alexander, C. L. Molecular Characterization of Cryptosporidium parvum Isolates from Human Cryptosporidiosis Cases in Scotland. Parasitology 2015, 142 (2), 318-325. https://doi.org/10.1017/S0031182014001346.

67. Chalmers, R. M.; Robinson, G.; Elwin, K.; Elson, R. Analysis of the Cryptosporidium Spp. and Gp60 Subtypes Linked to Human Outbreaks of Cryptosporidiosis in England and Wales, 2009 to 2017. Parasit. Vectors 2019, 12 (1).

https://doi.org/10.1186/S13071-019-3354-6.

68. Waldron, L. S.; Dimeski, B.; Beggs, P. J.; Ferrari, B. C.; Power, M. L. Molecular Epidemiology, Spatiotemporal Analysis, and Ecology of Sporadic Human Cryptosporidiosis in Australia. Appl. Environ. Microbiol. 2011, 77 (21), 7757. https://doi.org/10.1128/AEM.00615-11.

69. Osman, M.; Safadi, D. El; Benamrouz, S.; Guyot, K.; Dei-Cas, E.; Aliouat, E. M.; Creusy, C.; Mallat, H.; Hamze, M.; Dabboussi, F.; Viscogliosi, E.; Certad, G. Initial Data on the Molecular Epidemiology of Cryptosporidiosis in Lebanon. PLoS One 2015, 10 (5). https://doi.org/10.1371/JOURNAL.PONE.0125129.

70. Xiao, L.; Zhou, L.; Santin, M.; Yang, W.; Fayer, R. Distribution of Cryptosporidium parvum Subtypes in Calves in Eastern United States. Parasitol. Res. 2006, 100 (4), 701-706. https://doi.org/10.1007/S00436-006-0337-2.

71. Thompson, H. P.; Dooley, J. S. G.; Kenny, J.; McCoy, M.; Lowery, C. J.; Moore, J. E.; Xiao, L. Genotypes and Subtypes of Cryptosporidium Spp. in Neonatal Calves in Northern Ireland. Parasitol. Res. 2007, 100 (3), 619. https://doi.org/10.1007/S00436006-0305-X.

72. Broglia, A.; Reckinger, S.; Cacció, S. M.; Nöckler, K. Distribution of Cryptosporidium 
parvum Subtypes in Calves in Germany. Vet. Parasitol. 2008, 154 (1-2), 8-13. https://doi.org/10.1016/J.VETPAR.2008.02.029.

73. Duranti, A.; Cacciò, S. M.; Pozio, E.; Egidio, A. Di; Curtis, M. De; Battisti, A.; Scaramozzino, P. Risk Factors Associated with Cryptosporidium parvum Infection in Cattle. Zoonoses Public Health 2009, 56 (4), 176-182. https://doi.org/10.1111/J.18632378.2008.01173.X.

74. Feltus, D. C.; Giddings, C. W.; Schneck, B. L.; Monson, T.; Warshauer, D.; McEvoy, J. M. Evidence Supporting Zoonotic Transmission of Cryptosporidium Spp. in Wisconsin. J. Clin. Microbiol. 2006, 44 (12), 4303. https://doi.org/10.1128/JCM.01067-06.

75. Nolan, M. J.; Jex, A. R.; Mansell, P. D.; Browning, G. F.; Gasser, R. B. Genetic Characterization of Cryptosporidium parvum from Calves by Mutation Scanning and Targeted Sequencing - Zoonotic Implications. Electrophoresis 2009, 30 (15), 26402647. https://doi.org/10.1002/ELPS.200900071.

76. European Centre for Disease Prevention and Control. Cryptosporidiosis - Annual Epidemiological Report for 2018. Annu. Epidemiol. Rep. Commun. Dis. Eur. 2021.

\section{FIGURE LEGENDS}

Figure 1. Geographic location of Cyprus in the East Mediterranean region and distribution of the cattle farms sampled.

Farms $1-8$ were located across the Nicosia district (green), while farms $9-10$ were located in the Larnaca district (orange).

\section{Figure 2. Cryptosporidium parvum subtype prevalence across Cypriot cattle farms.}

Geographical distribution of $g p 60$ subtypes across Cyprus cattle farms: IIaA12G1R1 (orange), IIaA14G1R1 (red), IIaA15G1R1 (blue), IIaA15G2R1 (green), IIaA18G2R1 (yellow). C. parvum positive samples with unsuccessful gp60 sequencing are indicated in grey.

Pie charts are proportional to number of $C$. parvum positive samples identified per farm. 
Table 1. Cryptosporidium spp. prevalence in Cypriot dairy farms.

\begin{tabular}{cccccc} 
& & \multicolumn{4}{c}{ Cryptosporidium spp. present } \\
\cline { 3 - 6 } Farm & $\begin{array}{c}\text { No. of } \\
\text { specimens }\end{array}$ & C. parvum & C. bovis & C. ryanae & $\begin{array}{c}\text { C. ryanael } \\
\text { C. parvum } \\
\text { co- } \\
\text { infection }\end{array}$ \\
\hline 1 & & & & & - \\
2 & 13 & 3 & - & 2 & - \\
3 & 11 & 2 & 2 & - & - \\
4 & 15 & - & 2 & 4 & - \\
5 & 25 & 7 & - & 3 & 1 \\
6 & 23 & 5 & 3 & 5 & 1 \\
7 & 19 & 3 & 2 & 1 & - \\
8 & 23 & 8 & - & 3 & - \\
9 & 41 & 13 & 3 & 2 & 3 \\
10 & 61 & 8 & 8 & 6 & - \\
Overall & 242 & 50 & 23 & 28 & 5 \\
\hline
\end{tabular}

Table 2. Number of Cryptosporidium parvum gp60 subtypes identified out of total C. parvum positive samples per farm.

\begin{tabular}{cc}
\hline Farm & $\begin{array}{c}\text { Subtypes } \\
\text { (no. of subtype/total } \text { C. parvum samples per farm) }\end{array}$ \\
\hline 1 & Unidentified (3/3) \\
2 & IIaA14G1R1 (2/2) \\
3 & IIaA15G1R1 (1/1) \\
4 & - \\
5 & IIaA14G1R1 (6/8), IIaA15G2R1 (2/8) \\
6 & IIaA14G1R1 (5/6), IIa15G2R1 (1/6) \\
7 & IIaA14G1R1 (6/8), IIaA18G2R1 (1/8), Unidentified (1/8) \\
8 & IIaA14G1R1 (2/3), Unidentified (1/3) \\
9 & IIaA12G1R1 (14/16) IIa15G2R1 (1/16), Unidentified $(2 / 16)$ \\
10 & IIaA14G1R1 (6/8), Unidentified (2/8) \\
\hline
\end{tabular}


Table 3. Polymorphisms in Cryptosporidium 18S SSU rRNA and gp60 gene sequences showing intra-species genetic variability.

\begin{tabular}{|c|c|c|c|c|}
\hline Gene & $\begin{array}{l}\text { Cryptosporidium } \\
\text { species/subtype }\end{array}$ & $\begin{array}{c}\text { GenBank } \\
\text { accession number }\end{array}$ & Polymorphisms ${ }^{b}$ & Reference sequence \\
\hline $18 \mathrm{~S}$ & C. parvum & OL348120 & $\mathrm{G} \rightarrow \mathrm{A}$, position 701 & AH006572.2 \\
\hline $18 \mathrm{~S}$ & C. ryanae & OL348112 & $\mathrm{T}$ insertion, position 490 & KF128756.1 \\
\hline Gp60 & $\begin{array}{c}\text { C. parvum } \\
\text { (IIaA12G1R1) }\end{array}$ & OL462923a & $\begin{array}{l}A \rightarrow G, \text { position } 183 \\
C \rightarrow T \text {, position } 721\end{array}$ & MW411017.1 \\
\hline Gp60 & $\begin{array}{c}\text { C. parvum } \\
\text { (IIaA15G2R1) }\end{array}$ & OL462910 & $\begin{array}{c}\mathrm{G} \rightarrow \mathrm{A}, \text { positions } 163 \text { and } 581 \\
\mathrm{~A} \rightarrow \mathrm{T} \text {, position } 639 \\
\mathrm{~A} \rightarrow \mathrm{G}, \text { position } 687\end{array}$ & DQ630518.1 \\
\hline Gp60 & $\begin{array}{c}\text { C. parvum } \\
\text { (IIaA15G2R1) }\end{array}$ & OL462917 & $\mathrm{T} \rightarrow \mathrm{C}$, positions 454 and 469 & \\
\hline Gp60 & $\begin{array}{c}\text { C. parvum } \\
\text { (IIaA15G1R1) }\end{array}$ & OL462922 & $\mathrm{C} \rightarrow \mathrm{T}$, position 753 & AB777872.1 \\
\hline Gp60 & $\begin{array}{c}\text { C. parvum } \\
\text { (IIaA18G2R1) }\end{array}$ & OL462903 & $\mathrm{T} \rightarrow \mathrm{G}$, position 375 & DQ630515.1 \\
\hline
\end{tabular}

\footnotetext{
${ }^{a}$ Though multiple identical sequences were found, only one accession number is given for simplicity

${ }^{\mathrm{b}}$ Positions indicate differences from the reference sequence
} 


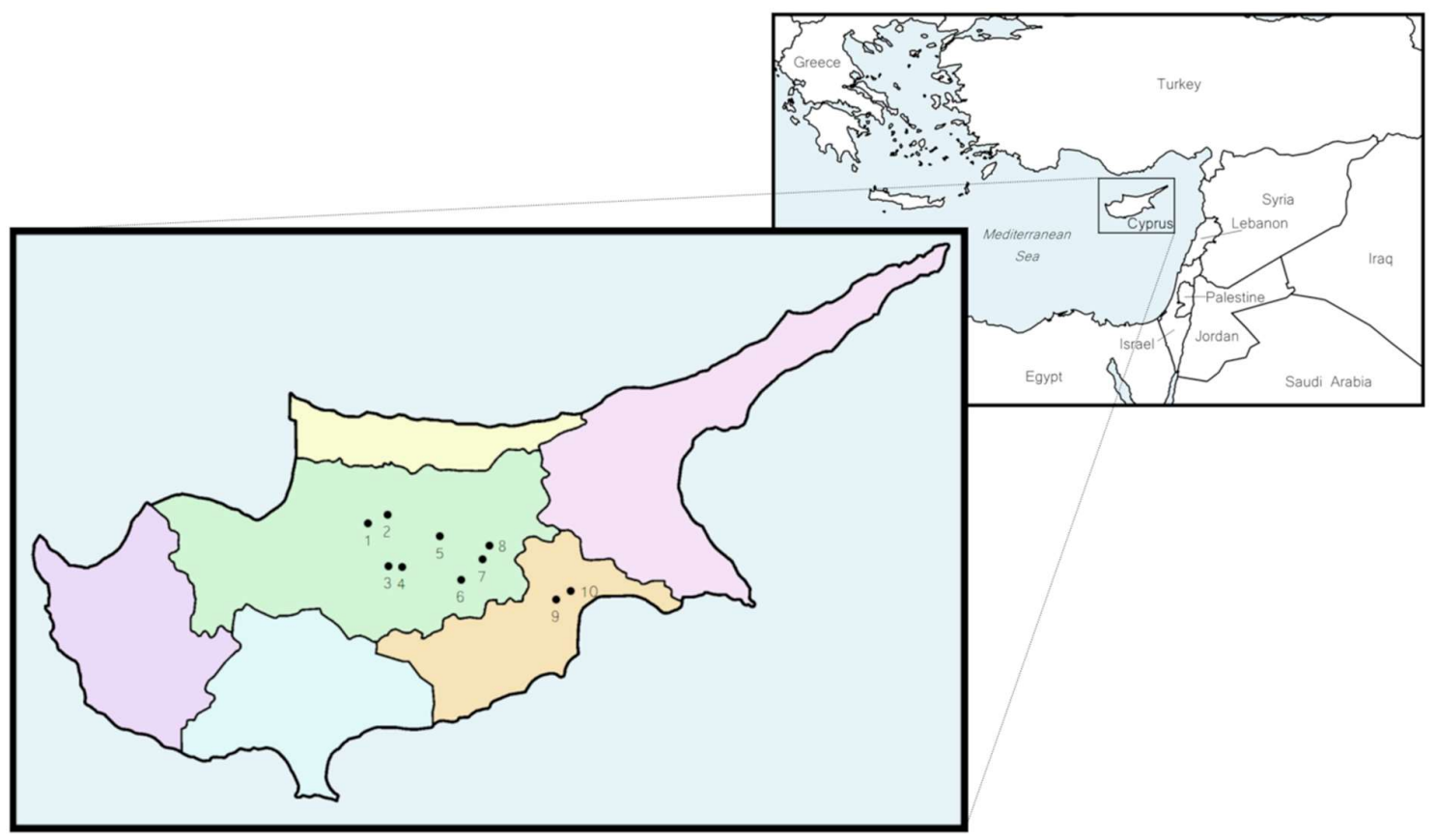

Figure 1. Geographic location of Cyprus in the East Mediterranean region and distribution of the cattle farms sampled.

Farms 1-8 were located across the Nicosia district (green), while farms 9-10 were located in the Larnaca district (orange).
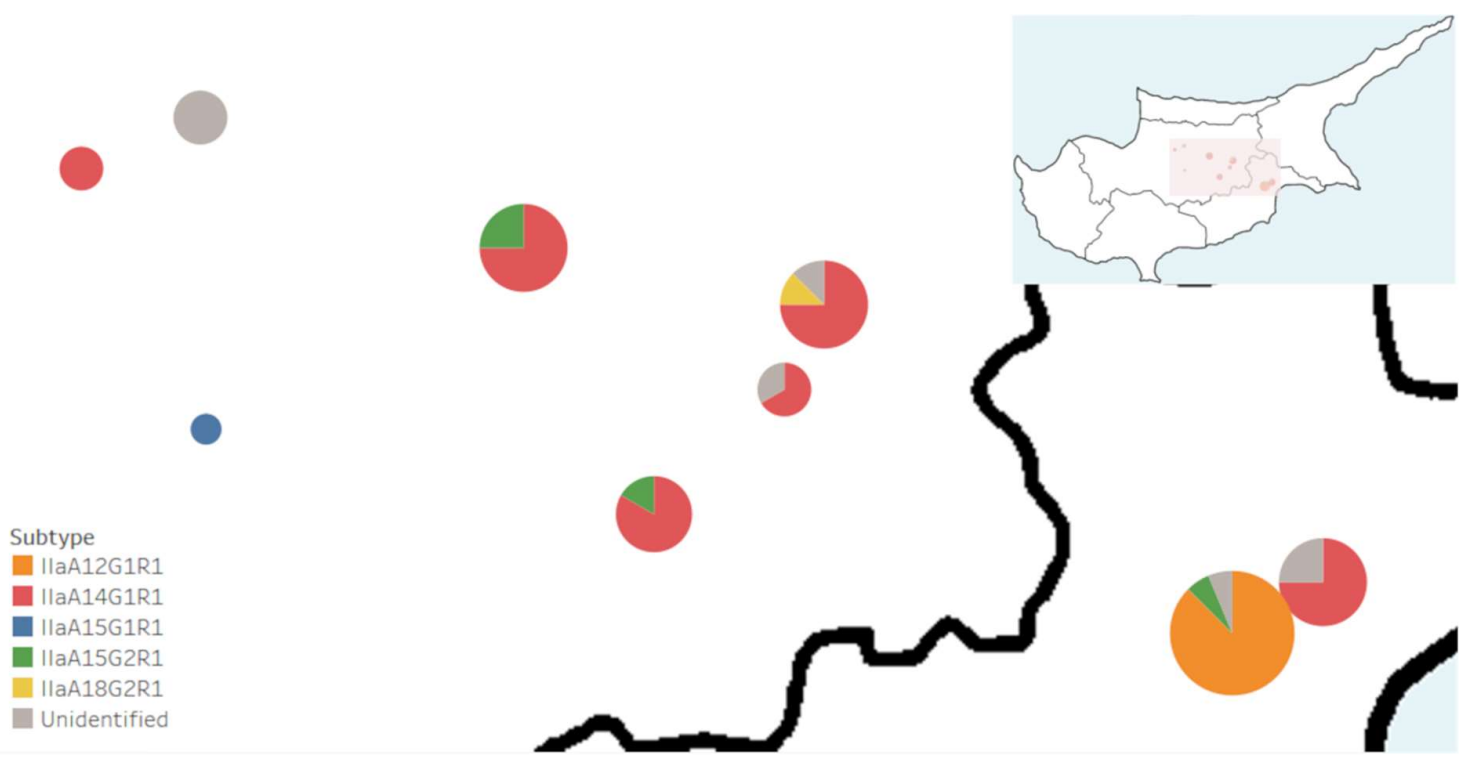

Figure 2. Cryptosporidium parvum subtype prevalence across Cypriot cattle farms.

Geographical distribution of gp60 subtypes across Cyprus cattle farms: IIaA12G1R1 (orange), IIaA14G1R1 (red), IIaA15G1R1 (blue), IIaA15G2R1 (green), IIaA18G2R1 (yellow). C. parvum positive samples with unsuccessful gp60 sequencing are indicated in grey.

Pie charts are proportional to number of $C$. parvum positive samples identified per farm.| 